\title{
Possibilidades de matricialidade na administração pública do lazer
}

\author{
Sílvia Cristina Franco Amaral* \\ Eduardo Tadeu Costa**
}

\begin{abstract}
Resumo: Este estudo partiu do entendimento de que o ciclo das políticas de lazer é implementado por diferentes setores da administração pública de forma isolada. Porém, o lazer é um processo que recebe influências de diferentes disciplinas que o configuram, tanto na teoria como na sua intervenção. $O$ objetivo desta pesquisa foi verificar a viabilidade da matricialidade para a condução de políticas públicas de lazer. Nós analisamos os dados com base na proposta de Martins (2005), que considera as estratégias, estrutura e o processo da matricialidade. Este artigo analisa os obstáculos estruturais, políticos, culturais, teóricos e subjetivos para este novo modelo de gestão. O mais importante obstáculo encontrado é o envolvimento de vários setores na matricialidade, pois este deveria se configurar com a mesma intensidade para todos os setores participantes. Contudo, isto não ocorre. De fato, não há uma equipe multidisciplinar de referência. Assim, é possível afirmar que este modelo precisa ser pensado como um programa de governo, não como ação isolada, em que diferentes setores se juntam para pensar algumas ações pontuais.
\end{abstract}

Palavras-chave: política pública-lazer-matricialidade

\section{INTRODUÇÃO}

Este texto é um extrato da pesquisa desenvolvida durante o período de janeiro de 2004 a janeiro de 2007, financiada pelo Programa de Políticas Públicas da Fundação de Amparo a Pesquisa do Estado de São Paulo (FAPESP). O estudo foi dividido em duas fases

\footnotetext{
‘Faculdade de Educação Física. Unicamp. Campinas, SP, Brasil E-mail: scfa@fef.unicamp.br "Faculdade de Educação Física-UNINOVE

Prefeitura de São Bernardo. São Bernardo, SP, Brasil. E-mail: tadeu@uninove.br
} 
intrinsecamente relacionadas. Partimos do pressuposto de que todo o ciclo ${ }^{1}$ das políticas públicas de lazer, nas cidades estudadas, era executado por diferentes setores da administração pública de forma isolada. A primeira fase do estudo coincide com o levantamento dos obstáculos à matricialidade e a segunda fase com o desenvolvimento de pesquisa-ação com as municipalidades envolvidas, implementando este modelo de gestão com os sujeitos participantes do estudo.

Este artigo diz respeito ao relato da primeira fase da pesquisa, na qual analisamos quais são os obstáculos estruturais, políticos, culturais, teóricos e subjetivos existentes naquelas cidades para este novo modelo de gestão.

\section{O PROCESSO DE LAZER E A MATRICIALIDADE}

\subsection{O PROCESSO DE LAZER}

O lazer não é uma manifestação que sempre existiu na história da humanidade. Não há como comparar os divertimentos, a própria organização dos tempos sociais e a sociedade produtiva da idade antiga e medieval com a vida social e os tempos da modernidade. A era moderna conferiu a forma do ser humano gerir sua vida qualidades próprias. Esta passou a ser vivida circunscrita a tempo e espaço específicos. $\mathrm{Na}$ modernidade, encontramos os sentidos e significados da separação entre tempo de trabalho e tempo livre de trabalho e, será neste último, que o lazer será organizado como uma atividade permitida, que visa educar, socializar e divertir, ou parafraseando Dumazedier (1979), para descansar, divertir e desenvolver. Também será na modernidade que visualizaremos o desenvolvimento do capitalismo, da industrialização, da urbanização e da modernização das cidades. Hoje, na "alta modernidade", todas estas características parecem acirradas, complexificando as relações

\footnotetext{
${ }^{1}$ Entendemos por ciclo de políticas públicas a elaboração, implementação, avaliação e reelaboração das mesmas, com ou sem a participação da população. Contudo, é primordial, para um processo que se quer democrático e articulado setorialmente, que a população esteja envolvida em todas as etapas deste ciclo.
} 
sociais. Desta forma, o ser humano é um homo urbanus, acometido pelo individualismo e sedentarismo. Muitas vezes, há pouco tempo e espaço para uma vida em coletividade. As decisões sobre os rumos da sociedade que "ontem" eram comunitárias, hoje sofreram dilapidações. Isto pode ser percebido pela pouca mobilização social de comunidades de bairros ou classista, no esvaziamento de locais públicos de lazer, no aumento da violência urbana, etc. O ser humano parece cada vez menos livre, cada vez menos partícipe da vida coletiva.

Contudo, este mesmo ser humano ainda continua necessitando do outro para se hominizar ${ }^{2}$ e humanizar. Ao entendermos o lazer, dentre outras manifestações sociais modernas, sob a égide do mundo do trabalho (alienado), racionalizado e produtivo, que acontecem fora deste tempo, mas que se configuram como constituinte dessa mesma lógica, com todas as suas ações definidas como parte da "recuperação para o trabalho", procuramos pensar numa racionalidade que nos leve a superar tal lógica. Nos pautamos pela contradição dialética que se define, essencialmente, como a unidade indissolúvel dos contrários e, também, ao trabalho do negativo, que implicará na inversão da dominância entre dois contrários até que se alcance a abolição de um e a emancipação do outro. O lazer tomado desde esta interpretação será a constante de afirmações e negações da lógica do trabalho alienado, um processo transformador, que cria uma história, tida como sempre aberta, que irá se configurar como um tempo e espaço liberador, no qual pode acontecer a organização da cultura e uma intervenção voltada à vida em coletividade.

\footnotetext{
${ }^{2} \mathrm{~A}$ expressão hominização é aqui usada para distinguir o ser humano de outros animais. Entende-se que o ser humano ao transformar a natureza através do trabalho concreto distinguese dos outros animais. Este ato permite que o ser humano haja consciente e racionalmente sobre seu ambiente natural criando condições artificiais de vida. A expressão hominização parte de uma lógica cultural, porque o ser humano ao transformar a natureza, além de criar ambientes artificiais de sobrevivência, também gera cultura, agrega-se racionalmente a outrem de sua espécie para sobreviver, porém mais do que isto, para desfrutar de uma vida confortável e prazerosa, que em condições naturais talvez não lhe fosse possível. Esta situação não pode ser encontrada em outros seres vivos.(BOTTOMORE, 2001)
} 
Em nossa opinião, o lazer acontece num tempo denominado livre, contudo não totalmente livre de coerções, assim só é possível entendê-lo como possibilidade latente de um tempo liberador, que pode construir um sentido de liberdade. Esta última será sempre auto e heterocondicionada ${ }^{3}$.

Os estudos do lazer e/ou as intervenções neste campo, tem recebido contribuições de diferentes disciplinas (como da educação física, turismo, sociologia, história, educação, arte, só para citar algumas), num caminho, que poderíamos denominar interdisciplinar e multiprofissional, entretanto, pensamos que já é possível, numa via de construção permanente, pensá-lo como um processo. Porque afirmamos isto? Tomando as contribuições de Silva (2002, p. 1) para pensar a saúde pública, e transportando-as para nossa área, o lazer é constituído pelo "entrecruzamento de diversas práticas (que) produz um novo enfoque, cujos limites são necessariamente indefinidos, e que se mantém aberto para receber outras influências das disciplinas que o constituíram e de novas disciplinas".

\subsection{Alguns apontamentos CONCEITUAIS ACERCA DA MATRICIALIDADE.}

O aparato estatal no Brasil vem passando por inúmeras transformações nos últimos anos, envolvendo maior diversidade e maior complexidade nos ambientes interno e externo, que levam a um constante reposicionamento de seus diferentes agentes sociais. Municipalização, globalização, revolução tecnológica e polarizações econômicas, acentuando abismos entre ricos e pobres, compõe o universo que atualmente se depara a administração pública. Nesse universo não são poucos os problemas que dificultam a capacidade de intervenção estatal.

Marini e Martins (2005, p. 236) apontam a fragmentação como uma das categorias centrais destes problemas, pois se trata de uma condição crítica que se refere a: "[...] falhas de coerência (políticas

\footnotetext{
${ }^{3}$ Munné (1980) irá usar estas categorias conceituais para explicitar a relação dialética que acontece no tempo livre. Para o autor autocondicionamento está na esfera do indivíduo e heterocondicionamento é tudo aquilo do coletivo que influi e determina o autocondicionamento.
} 
e programas que não convergem com objetivos comuns), de coordenação (dificuldade para articular e convergir ações) e de consistência (ações que se anulam reciprocamente)."

Ao propor uma metodologia de gestão para o trabalho interdisciplinar em saúde pública, Gastão Campos e Ana Domitti descrevem obstáculos epistemológicos e estruturais que se apresentam àqueles que se dispõe a enfrentar os aspectos negativos gerados pela fragmentação nas políticas públicas: Obstáculos estruturais, relacionados ao elevado grau de departamentalização, à lógica corporativa e das profissões; Obstáculos decorrentes do excesso de demanda e da carência de recursos; Obstáculo político e de comunicação, que consideram a concentração de poder em algumas funções e a restrição à circulação de informações e contatos interprofissionais; Obstáculo subjetivo e cultural, relativo à indisposição subjetiva em se lidar com a incerteza, receber e fazer críticas e para a tomada de posição de modo compartilhado. Também não há cultura organizacional entre os gestores sobre métodos para programar trabalho integrado; Obstáculo ético, diz respeito, em saúde, à privacidade da história do paciente, da família ou de grupos que o trabalho matricial poderia trazer alterações; Obstáculo epistemológico, ligado ao predomínio da racionalidade biomédica, que se baseia num referencial sobre o processo de saúde e doença restrito bem como outros referenciais. (CAMPOS; DOMITTI, 2007).

Humberto Martins (2005, p. 281) ao questionar-se sobre quais fatores estruturais explicam determinado grau de fragmentação dos processos de implementação de políticas, resume sua resposta do seguinte modo: "[...] a principal proposição causal/ associativa de uma teoria da fragmentação de políticas públicas dá-se entre estruturas e processos: arranjos estruturais fragmentadores geram processos fragmentadores, que, por sua vez, geram políticas fragmentadas".

Diante deste quadro, buscar formas inovadoras para dar conta de suas novas responsabilidades, bem como para superar as características críticas peculiares de seu padrão organizacional faz- 
se necessário para criar o reconhecimento do governo municipal, no Brasil, como uma unidade básica de acumulação social (DOWBOR, 1996.)

Diante dessa necessidade de alteração, Marini e Martins (2005) propõem o funcionamento do Estado como rede, mostrando-se favoráveis às concepções de governança social baseadas em arranjos multiinstitucionais entre governos, mercado e sociedade civil. Menos hierárquico e mais cooperativo, articulado na tomada de decisões, este Estado-rede caracteriza-se pelo compartilhamento de autoridade entre instituições. Para esses autores, ao tratarmos de uma administração em rede, faz-se necessário tratarmos também de integrar estabilidade e crescimento econômico; do incremento sustentável de bem-estar geral em termos de desenvolvimento humano; e da sustentabilidade ambiental.

Emerge a ideia do poder público municipal como um articulador, que reconhece a existência de outros agentes sociais interessados na melhoria da qualidade de vida nas cidades, e como um negociador, que firma projetos comuns com as diversas instituições locais. Concertadora $^{4}$ de interesses e de recursos, a municipalidade cumpre seu papel também ao fomentar redes de cooperação entre diferentes instâncias de governo, universidades, sindicatos, empresários e demais atores da sociedade civil, bem como buscando associação com outros municípios para a resolução de problemas comuns.

Ganha pertinência a compreensão de um governo local que se preocupe com a criação de mecanismos participativos simplificados e diretos tanto com a população, quanto com os demais agentes do município, visando à formulação e à provisão de serviços públicos; que aposte numa comunicação mais ágil com os cidadãos e que estimule e possibilite o controle social por intermédio da participação de comitês e conselhos comunitários dos segmentos interessados.

${ }^{4} \mathrm{O}$ termo concertador é usado aqui no sentido de buscar a composição de diferentes interesses e recursos por intermédio da criação de arranjos, acordos e pactos. 
Este novo papel do Estado no âmbito local, protagonista, destaca também a importância em se implementar novos arranjos internos no aparato estatal, vislumbrando a criação de inteligência estratégica que, por meio de articulações intersetoriais, promova ações conjuntas entre os diferentes programas de um mesmo município, otimizando a organização da administração direta, tornando-a mais horizontal, diminuindo a fragmentação entre seus órgãos funcionais e maximizando a coordenação, a consistência e a coerência na aplicação dos recursos públicos.

Pensar a administração pública como matriz remete-nos inicialmente, considerado o sentido literal do termo, a imaginá-la como o lugar no qual algo se gera ou se cria. Vislumbra-se o governo matricial como uma plataforma de implementação voltada para resultados de desenvolvimento, que se baseia na definição e no gerenciamento intensivo de pontos nodais entre programas e organizações. (MARINI; MARTINS, 2005).

Ao discutir o apoio matricial como metodologia para a gestão do trabalho interdisciplinar em saúde, Campos e Domitti (2007) atentam para a necessidade de elaboração de síntese nesta dinâmica. $\mathrm{O}$ apoiador matricial ${ }^{5}$, ao procurar construir de maneira compartilhada projetos de intervenção com outros interlocutores, deve valer-se, de maneira dialógica na relação entre os sujeitos participantes, dos distintos papéis, saberes e valores presentes.

Ao mesclar participação com busca de produtividade e compromisso, essa proposta simultaneamente atuaria no sentido da produção do sujeito e do coletivo organizado. Vislumbra-se a montagem de uma máquina organizacional que permita ao trabalhador seu crescimento pessoal e coletivo e ao mesmo tempo seja produtora de bens e serviços públicos. Espaços co-produtores de sujeitos aptos para assumir os riscos e o prazer da criação e, também, preparados

\footnotetext{
${ }^{5} \mathrm{O}$ apoiador matricial é um especialista que tem um núcleo de conhecimento e um perfil distinto daquele dos profissionais de referência, mas pode agregar recursos de saber e mesmo contribuir com intervenções que aumentem a capacidade de resolver problemas de saúde da equipe primariamente responsável pelo caso. (CAMPOS; DOMITTI, 2007, p. 401)
} 
para contratar compromissos e respeitar a missão primária da instituição em que se inserem. Deste modo, seriam construídas sínteses sucessivas, porém provisórias, na medida em que seriam instauradoras de outros conflitos que estimulariam outros movimentos. (CAMPOS, 1998).

A construção desses espaços, envolvendo a idéia de conflito, deve considerar que seus sujeitos têm graus bastante variados de condições de poder, determinados pela ausência estrutural de equiidade, implicando assim o enfrentamento dessas contradições. Implica também que, configurando-se como espaço de negociação, exista a disposição para repartição e compartilhamento de poder visando à possibilidade de uma ação mais potente.

Verificamos assim uma compreensão sobre a gestão de políticas públicas, materializada no desenvolvimento de uma nova prática social em construção que, ao enfrentar a realidade social com base em temas mobilizadores, por meio da articulação de saberes, de poderes, de sujeitos e de organizações, originam-se em espaços coletivos nos quais a negociação, ao mesmo tempo em que produz o crescimento de sujeitos e de coletivos organizados, origina um bloco orgânico e sistemático de políticas, voltados para o alcance de resultados que visam superar a exclusão social e garantir a melhoria da qualidade de vida.

Articulação, confiança, coordenação, negociação, cooperação, interconexão, equilíbrio, construção de relações e busca de resultados, entre outros, são elementos exigidos para a criação e implementação de instrumentos voltados para a intervenção nesta dada realidade. Configurada deste modo, a ação matricial apresenta-se como potencial alternativa metodológica. 


\section{MatricialdDADE NAS POLÍticAS PÚBLICAS DE LAZER EM SANTO ANDRÉ E ITAPIRA?}

As administrações municipais nas quais desenvolvemos o estudo foram as de Itapira e Santo André, ambas as cidades do estado de São Paulo. A escolha das cidades se deu pelo interesse e envolvimento de dirigentes do campo do lazer ${ }^{6}$. Estes, em certa medida, já se perguntavam o que buscamos responder na primeira etapa do estudo, ou seja, porque há ações de lazer planejadas e implementadas de forma fragmentada em diferentes setores da administração?

Embora a escolha tenha seguido o critério de interesse e disponibilidade dos dirigentes responsáveis diretos pelas ações de lazer, conseguimos contemplar uma diversidade de fatores importantes ao estudo: as duas cidades possuem diferenças ideológicas que sustentam as gestões (Itapira e Santo André eram dirigidas majoritariamente pelo PSDB e PT, respectivamente), apresentam também diferenças estruturais, territoriais e em seu número de habitantes. Itapira é uma cidade de pequeno porte, considerada sua população, mas possui uma grande área territorial, já Santo André é uma cidade de porte médio para grande, mas possui uma área territorial bastante compacta. Além disso, outra característica marcante é o estilo de vida de seus habitantes: Itapira é uma cidade na qual a vida comunitária parece assumir um papel central. Santo André - até mesmo pela proximidade com São Paulo - apresenta um cotidiano típico de cidade grande, no qual os cidadãos têm pouco tempo livre de trabalho. Outra característica marcante na população de Santo André é que muitos cidadãos, que lá vivem, trabalham em cidades vizinhas e, também há muitos trabalhadores em Santo André que provém de outros centros.

\footnotetext{
${ }^{6}$ Quando falamos em campo do lazer é para não perder de vista a perspectiva teórica que usamos neste estudo, isto não significa que os municípios estudados tenham em suas perspectivas conceituais este entendimento. Quando falamos de dirigentes deste campo, estamos nos reportando aos que nominalmente respondem por departamentos que um dos temas é o lazer (como é o caso de Santo André) ou mesmo, por departamentos isolados (como era o caso de Itapira até a criação da Secretaria de Esportes e Lazer no início de 2005).
} 
A pesquisa foi desenvolvida durante seis meses (de março a agosto de 2004). Para balizar o trabalho e tecer conclusões que nos permitiram desenvolver ferramental para transferência de tecnologia específica ao planejamento, execução e avaliação de políticas públicas na área do lazer, nos colocamos três perguntas centrais: (1) quais são os órgãos provedores de lazer dentro da administração pública municipal? (2) quais são os modelos de gestão colocados em prática nesses órgãos que oferecem oportunidades de lazer aos munícipes de suas cidades? E, (3) quais são os obstáculos estruturais, conjunturais e conceituais para viabilizar um modelo de gestão que promova a realização de ações transversais na formulação, implementação e avaliação de políticas públicas de lazer nos municípios?

Adotamos para a coleta de dados, além das reuniões, três modelos de instrumentos de pesquisa: um que privilegiou a análise de documentos que julgávamos importantes (Lei Orgânica Municipal; Orçamento Geral do Município e especificações orçamentárias da área do lazer; Plano de Governo; PPDA; Plano Diretor; Plano de Trabalho do Setor do Lazer) ; um formulário de avaliação de recursos humanos, físicos e financeiros dos setores que promovem ações de lazer e um mapa de programação de lazer oferecido anualmente por cada um dos setores, de cada cidade, que se envolveu na pesquisa. Também, elegemos quatro textos sobre lazer e políticas públicas para sustentar as discussões conceituais que promovemos.

Ao final da primeira fase do estudo constatamos que vários setores, que não tem como objeto central de intervenção o lazer, nas cidades estudadas, promovem alguma ação ligada ao campo - direta ou indiretamente. Como exemplo, a educação, a saúde, o turismo, o meio ambiente, entre outros, são áreas que atuam com lazer. Os dados das cidades pesquisadas apontam que há um envolvimento em torno de $12 \%$ dos recursos humanos de vários setores nas ações desenvolvidas que tem relação direta ou indireta com o lazer. Além disso, se tomarmos ações indiretas, o orçamento estimado, envolvido neste campo, fica em torno de $10 \%$ do total geral da administração municipal. Contudo, outra constatação importante é que dada à 
dificuldade de realização de ações intersetoriais, estes recursos humanos com apoio financeiro e físico de toda ordem, despendem esforços que resultam em ações fragmentadas, com grandes limitações teóricas, cujos planos e programas de ação, se tornam apenas instrumento burocrático.

A gestão apresenta diversos programas ligados ao lazer, desenvolvidos por diferentes setores. Ao analisarmos os classificamos em sem interlocução, com sobreposição e com interlocução. Os programas sem interlocução eram aqueles em que apenas um setor era responsável pelo mesmo. Os programas com sobreposição eram aqueles desenvolvidos por diferentes setores em épocas diferentes ou na mesma época, mas com o mesmo tema central. Desta forma, fica a impressão de que não há comunicação entre os setores, que optam por tratar do mesmo tema isoladamente. Por fim, os programas com interlocução diziam respeito aqueles que apareciam em mais de um setor com o mesmo nome e na mesma época. Porém, nem sempre ficava claro qual era a forma de interlocução existente (se era direta ou indireta) ou o nível de envolvimento de cada setor no evento ou programa (planejamento, organização, execução e controle/ avaliação).

O que dizemos acima pode ser constatado em números, nos programas encontrados nas duas cidades, na ocasião da pesquisa. Em Itapira, os programas que se sobrepunham podem ser mais encarados como eventos, do que de fato programas e, no ano analisado, eram em número de quatro (4). Não foi possível verificar nenhum nível de interlocução entre os mesmos. Os programas com interlocução eram em número de trinta e nove (39), mas da mesma forma que os programas em sobreposição, podem ser encarados mais como eventos pontuais. Além disso, cabe pontuar que na sua maioria os programas eram "puxados" por um departamento com auxílio dos demais. Este auxílio era mais em relação a cedência de recursos humanos, financeiros e materiais para a realização do mesmo, do que a uma discussão conjunta do processo de planejamento, execução e avaliação destes programas.Os programas sem interlocução encontrados totalizaram trinta e três (33) e, destes 
$40 \%$ ainda caracterizados como eventos pontuais. Os programas permanentes de atendimento ao cidadão eram todos executados por um único órgão da administração municipal. Certamente todos estes dados mostram a fragilidade das ações de lazer na cidade de Itapira. Mas o que mais chamou nossa atenção é o número de equipamentos públicos de lazer existentes naquela cidade.

No tocante aos recursos físicos, as únicas instalações que são usadas por mais de um departamento para o mesmo fim (prática esportiva) são as quadras poliesportivas das escolas municipais de ensino fundamental (EMEF), que são utilizadas pelos departamentos de Educação Fundamental e o de Recreação, Esporte e Lazer. Os demais espaços são utilizados por apenas um departamento, sendo que o Departamento de Segurança está presente em praticamente todos os espaços, apenas para vigilância. O Departamento de trânsito esta presente em todas as vias e logradouros públicos também apenas para sinalização. O Departamento de Desenvolvimento, Econômico, Social e Turismo trás em sua relação de espaço físico uma praça, um parque e 60 escolas, espaços que teoricamente seriam utilizados por mais de um setor, porém não trás maiores especificações sobre suas utilizações. Os demais espaços utilizados para o lazer são: três postos de saúde, três anfiteatros, dois cinemas, oito centros comunitários multifuncionais, uma biblioteca, um espaço multifuncional de cultura, três museus e por informação do Departamento de Recreação, Esporte e Lazer, naquela ocasião a cidade contabilizava 200 (duzentos) equipamentos públicos de lazer.

Em Santo André, os recursos físicos para o lazer também eram numerosos. Totalizavam 11 parques, 500 praças, Paço Municipal, 3 teatros, museu, Casa da Palavra, Casa do Olhar, 2 Escolas de Iniciação Artística, 13 Piscinas, 8 Ginásios e 45 Campos, Núcleo de Apoio à Natação Adaptada, Ginásio de Skate, 1 Centro de Dança, 9 Centros Educacionais de Santo André, 4 centros comunitários, Centro de Referência da Juventude, Centro de Referência da Infância, Escolas Municipais de Educação Infantil e de Ensino Fundamental, Unidade de Saúde e Vila de Paranapiacaba. Há também uma tendência aos mesmos problemas apresentados em Itapira quanto à 
forma de organização dos programas de lazer. Cabe, entretanto, uma ressalva, quando falamos da cidade de Santo André. Havia um programa matricial denominado Santo André Mais Igual. Este programa denota o esforço daquela municipalidade para implementar a matricialidade nas políticas publicas e o lazer tem importância garantida no programa.

Todos estes dados nos levaram a outra informação de extrema relevância para pensarmos em obstáculos a matricialidade, pois com uma fragmentação explícita nas gestões, decorre daí um outro problema, o da precária comunicação e cooperação intersecretarias. Isto configura um quadro nos quais muitas secretarias (ou departamentos) não promovem ações que não estejam sob sua tutela. Parece que tal conjuntura denota uma incapacidade dos sujeitos de trabalharem coletivamente, descrevendo um singular jogo de vaidades e centralidades o que pode tornar a gestão pública, e seus serviços, patrimônios particulares de alguns grupos e/ou pessoas. Isto nos permite pensar que a administração pública não incorporou a idéia de "processo de lazer", nem tampouco tem entendido esta manifestação como uma prática multiprofissional e multidisciplinar, pois, como foi colocado anteriormente, o lazer recebe contribuições de diferentes disciplinas e é constituído pelo entrecruzamento de diversas práticas que irão produzir um novo enfoque, um novo olhar, sobre esta manifestação. Além disso, se assim encarado, o lazer não é um campo homogêneo, mas se configura por metas e eixos de ação que devem ser construídos conjuntamente por todos os profissionais que intervêm nestas políticas.

Além dos sujeitos da administração direta destas ações, procuramos também conhecer quais obstáculos provém das comunidades e que podem interferir na matricialidade. Primeiro, constatamos que nem todas as comunidades se envolvem na reivindicação, fiscalização da gestão ou mesmo, na participação, quando há esta abertura nas gestões. Quando há envolvimento da comunidade, através de suas lideranças, nem sempre estas estão preocupadas com a melhoria da comunidade e da coletividade. Podemos identificar pelo menos três tipos de lideranças comunitárias. 
Os primeiros são aqueles que buscam o envolvimento comunitário para tratar de um interesse imediato, de uma necessidade que ocorre no entorno de sua residência, como por exemplo, o calçamento da sua rua, a escola para seu filho, etc. Este tipo de liderança tão logo satisfeita sua necessidade deixa de atuar como líder. O segundo tipo é aquele que busca autopromoção e, na maioria das vezes, sua ação visa um futuro ingresso na carreira política. Não estamos afirmando com isto, que este tipo de liderança não possa e não pense sua comunidade, mas quando o interesse é somente individual, sendo seu líder incapaz de ouvir aqueles a quem representa, verifica-se a tendência ao carreirismo político. $O$ terceiro e, último tipo, é aquele que ouve a comunidade na qual está inserido, busca representá-la (independente de cargos políticos que venha por ventura assumir) e muitas vezes têm de deixar seus interesses pessoais de lado para atender aos da coletividade.

\section{Considerações finals}

Resumidamente podemos afirmar que entre os obstáculos para a implementação da matricialidade estão o número de programas de lazer dispersos existentes nos diferentes órgãos da administração pública, a fragilidade conceitual e política com que as políticas de lazer são encaradas, a baixa cooperação institucional existente entre os órgãos municipais, as disputas de um poder político (a correlação de forças e demarcação de espaços por diferentes grupos numa mesma gestão) que pensa mais em elegibilidade do que em governabilidade. Decorre daí uma baixa possibilidade de envolvimento das comunidades e os mesmos vícios da administração pública nos cidadãos, que se autodenominam participativos.

Assim, pensamos que a matricialidade só poderá ser de fato uma mudança política substancial quando tais obstáculos forem superados e o lazer, ou qualquer outra política social, passe a ser encarada como ação de governo e não de grupos dispersos em interesses difusos. 
Possibilities of matrix support in leisure public administration

Abstract: This study assumes that the cycle of leisure public policies was implemented by different sectors of public administration in an isolated form. But, leisure is a process that receives influences from several subjects that constitutes both a theoretical field and an intervention. The purpose of this research was to get know the viability of the matrix management for conducting leisure public policies. We have analyzed the data based on the script of Martins (2005), who is concerned with the strategy, structure and process of the matrix management. This article analyzes the structural, political, cultural, theoretical, and subjective obstacles to this new model. The most important obstacle is the involvement of the various sectors in the matrix model. These sectors do not get involved in this policy with the same intensity. In fact, there is no interdisciplinary team reference. This way, we believe that this model must be thought as a government action, rather than an isolated action with team from several sectors.

Keywords: public policies - leisure - matrix management

Posibilidad de la matricialidad en la
administración pública del ocio

Resumén: Este estudio se inició a partir del supuesto de que el ciclo de políticas de ocio está formado por diferentes sectores de la administración pública de forma aislada. Aun así, el ocio es un proceso que recibe influencias de las diferentes disciplinas que lo configuran, tanto en la teoría, como en su propia intervención. El objetivo de esta investigación fue verificar la viabilidad de la matricialidad para la dirección de políticas públicas de ocio. Analizamos los datos basándonos en la propuesta de Martins (2005), que considera las estrategias, estructura y el proceso de matricialidad. Este artículo, analiza los obstáculos estructurales, políticos, culturales, teóricos y subjetivos para este nuevo modelo de gestión. El obstáculo de mayor importancia encontrado, es la implicación de varios sectores en la matricialidad, ya que este debería configurarse con la misma intensidad en todos los sectores partícipes. Sin embargo, esto no ocurre. De hecho no hay un equipo multidisciplinar de referencia. Asimismo, es posible afirmar que este modelo necesita ser pensado como un programa de gobierno, no como una acción aislada, en la que diferentes sectores se juntan para pensar determinadas acciones puntuales. Palabras clave: política pública-ocio- matricialidad 


\section{REFERÊNCIAS}

BOTTOMORE, Tom. Dicionário do Pensamento Marxista. Rio de Janeiro: Zahar,2001.

CAMPOS, Gastão W. S. O anti-Taylor: sobre a invenção de um método para cogovernar instituições de saúde produzindo liberdade e compromisso. Caderno de Saúde Pública, Rio de Janeiro, v. 14, n. 4, p. 863-870, out./dez. 1998.

CAMPOS, Gastão W. S.; DOMITTI, Ana C. Apoio matricial e equipe de referência: uma metodologia para a gestão do trabalho interdisciplinar em saúde. Caderno de Saúde Pública, Rio de Janeiro, v. 23, n. 2, p. 399-407, fev. 2007.

DOWBOR, Ladislau. Governabilidade e descentralização. Revista da Fundação Seade, São Paulo, vol. 10, n. 3, p. 21-31, jul./set.1996.

DUMAZEDIER, Jofre. Sociologia empírica do lazer. São Paulo: Perspectiva, 1979.

MARINI, Caio; MARTINS, Humberto F. Um Governo Matricial: Estruturas em rede para gerar resultados de desenvolvimento. In: LEVY, Evelyn; PRAGO, Pedro Anibal (Org). Gestão Pública no Brasil Contemporâneo. São Paulo: FUNDAP, Casa Civil, 2005.

MARTINS, Humberto F. Fragmentação e intersetorialidade: em busca de uma agenda de integração. In: LEVY, Evelyn; PRAGO, Pedro Anibal (Org). Gestão Pública no Brasil Contemporâneo. São Paulo: FUNDAP, Casa Civil, 2005.

MUNNÉ, Frederic. Psicosociología del tiempo libre: un enfoque crítico. México, D.F.: Editorial Trillas, 1980.

SILVA, Claudia Osório da. Vida de hospital: a produção de uma metodologia para o desenvolvimento da saúde do profissional de saúde. 2002, 128 p. Tese (Doutorado) Fundação Oswaldo Cruz, Escola Nacional de Saúde Pública; Rio de Janeiro, 2002.

Apoio: FAPESP

Recebido em: 25-03-2011

Aprovado em: 12-03-2012 
